\title{
From cats to roller-coasters: creative use of posters to explore students' perceptions of PDP
}

\author{
James Davey \\ University of Central Lancashire (UCLan), UK \\ Peter Lumsden \\ University of Central Lancashire (UCLan), UK
}

\section{Abstract}

As in many other UK institutions, the implementation of Personal Development Planning (PDP) has been varied across the University of Central Lancashire (UCLan). This is due to a number of factors, including a limited understanding by staff of the underlying principles of reflection and their own personal development as practitioners. In the past, workshops with staff on PDP were often met with resistance and poor attendance. As an alternative, we have sought student perceptions of PDP, in the hope that these could be used to engage and influence members of staff. Year one students from ten different courses were given a session on PDP at the end of which they produced posters representing their perceptions of PDP for their course. The terms in these posters were coded and placed in appropriate categories then ranked to allow for comparisons between groups. Individual priorities for immediate action were captured on post-it notes. A year later the same students were surveyed once again and individual perceptions were captured by a questionnaire. Groups were shown their original poster and asked to create a new poster in the light of a year's experience.

First years' posters had elements of theoretical frameworks for PDP, with about half showing an idea of progressive development over time; posters from second years were less theoretical and instead reflected real-life experiences, with fewer terms but more extensive wording, and less focus on stages of development and forward planning. Second year students also showed evidence of engaging in PDP at an individual level with many reporting achievements in aspects such as time management which they had mentioned in year one. We conclude that students are able to recognise 
their development needs, and their achievements, but that the planning element of PDP is less well recognised.

Keywords: PDP; student perceptions; posters; reflection; personal development; situated learning.

\section{PDP in context - engaging staff}

Although the current agenda around PDP dates back to the Dearing report of 1997 (Dearing, 1997) a historical glance indicates that in some ways we have come full circle. Writing in the $19^{\text {th }}$ century, Newman noted that 'UK higher education has placed considerable emphasis on the personal development of its students' (Brennan and Shah, 2003). Today the role of many universities has broadened from a singular focus on research and teaching to also include widening access and enhancing employability (Bloxham et al., 2007). So Newman's concept of personal development has become important again, not least as one way of increasing retention of 'non-traditional students' (Warren, 2003, cited in Bloxham et al., 2007).

However, despite external drivers to have PDP implemented across all universities by 2006 (Clegg and Bradley, 2006), implementation has been varied. One of the barriers has been staff's own approach to their own continuing personal and professional development (CPPD) because, according to Stefani (2005, p.4), 'academic staff do not see the 'reward' for engaging in CPD'. If staff have problems engaging in reflective practices this reduces the perceived rewards of helping students engage in PDP (Stefani, 2005). As a result, staff do not intuitively embrace the concept of PDP. It can also be seen as an additional activity, creating extra work (Moir et al., 2006), and /or which takes up teaching time. The fact that PDP could be perceived as the result of external influences is well described by Moir et al. (2006, p.1):

The danger with such prescriptive approaches is that PDP may come to be seen as an imposition rather than something integral to the higher education experience. 
It is possible that these negative views and feelings are communicated to students which would inevitably reduce the likelihood of their engaging with PDP in a meaningful way.

During my time as an educational developer, several attempts have been made to engage staff in discussion of PDP, mainly through departmental and faculty workshops. However, these sessions have been met with poor attendance and sometimes with resistance from staff. To demystify the idea of PDP we operationalised the concept in terms of five elements - self awareness, reflection, action planning, team/group work, and career planning (Lumsden, 2005) - and this deconstruction has now been taken forward across the university. As elsewhere, PDP practices vary across courses and schools. In some it is assessed and is considered to be part of the course, others offer incentives to engage in PDP, while for others the personal tutor has a key role in guiding students in PDP practices. Thus there is a mixture of embedded and bolt-on approaches. Whilst there has been evidence of some changes in practice taking place, the dissemination/sharing of good PDP practices is limited. Because of the resistance and lack of engagement of staff and the limited sharing of practice taking place, an alternative approach was considered.

\section{Rationale for the new approach}

This study began with a PDP session with a group of first year Bioscience students in 2007 , and resulted in the production of a series of posters of PDP. On becoming part of the NARN (National Action Research Network - Researching and Evaluating PDP and e-Portfolios) project it seemed an opportunity to extend this approach to other courses, and then to see if these visual images proved effective in engaging staff in discussion and thinking about their practice.

Aside from using the material as an aid for staff development, we were interested to see how students' perceptions evolved over time. We therefore revisited the same cohorts of students in their second year, repeating the activity. Here we report on this approach to soliciting the views and perceptions of PDP of students on different courses and at different levels, and present an analysis of the responses. We will report on how this material has subsequently been used in staff development sessions. 


\section{Method}

In the first part of the study, first year undergraduates, mainly attending courses in the faculty of science, were recruited during a pre-organised PDP session. Students gave informed verbal consent that the work they were about to produce could be used as data in a national research project. Next they were given a hand-out defining and describing the five elements of PDP referred to earlier (Lumsden, 2005), and a short presentation on PDP and emotional intelligence. Following the presentation, students were placed in groups of three to five and carried out a skills audit. The outcomes of this exercise were discussed, collated and displayed on a flip-chart/white board. Finally, the groups were given the task of representing their ideas and perceptions about PDP, focusing on where and how the various elements might occur and be supported during their time at UCLan. These representations were in the form of posters drawn on flipchart paper using marker pens. At the end of the session students also wrote on individual post it notes, stating 'one thing I am going to do/address as a result of today'.

A year later the same students were revisited. They filled out a short questionnaire to assess whether their expectations of PDP had been met, exceeded, or not met. They were then shown their posters from the first year, asked 'In the light of a year's experience, how would you amend/update that poster?', and they then produced new posters.

A form of textual analysis - grounded theory (Strauss, 1987) - was conducted on the data. For each course the terms from all the posters were collected and entered into a single table. These terms were then placed into categories with a single underlying theme. Successive readings and re-classifying reduced the data to ten categories, shown in Table 1. The courses included in the analysis were Archaeology, Biomedical Sciences, Biosciences, Building Services, Forensic Science, Pharmacy, Retail Management and Foundation Degree (FD) Health and Social Care. The number of posters varied depending on the size of cohort, for example, fourteen from first year Forensic Science students, and just one from second year Health students. 
Table 1. Categories used to describe terms from posters.

\begin{tabular}{|l|l|}
\hline Category & Brief description (examples of terms used by students) \\
\hline Personal & Personal growth; self-confidence \\
\hline Academic & Note taking; referencing skills \\
\hline Team/group work & Ability to work in group situations; team building \\
\hline Career planning & Work experience; pre-registration \\
\hline Reflection & SWOT; skills audit \\
\hline Action planning & Help with revision; if something is unclear inform the teacher \\
\hline Social/support & Friends; meet new people \\
\hline Academic support & Tutors; the 'l' \\
\hline Requests & Approachable staff; extra skill options \\
\hline Complaints & More organisation from UCLan; repetitive teaching topics \\
\hline
\end{tabular}

For each group of posters from a course we ranked the categories by frequency of appearance of the terms. The top category accounted for about $25 \%$ of the terms; the second category for a further $20 \%$, and the third category for another $15 \%$, and we have restricted our analysis to these top three.

\section{Appearance of posters}

The way in which first year students represented their idea of PDP in the posters varied. A few simply followed the explanation sheet given to them, which gave the QAA (2009) definition of PDP and the five terms identified by Lumsden (2005) as constituting PDP, which were: self-awareness, reflection, action planning, team/group work, and career planning. They recapitulated these terms as five sections on the poster. Others drew a more complex diagram, with a combination of text and images. This was the most common type of representation; most contained an element of progression, or were a type of mind map. A small number of students represented their perceptions wholly pictorially; although these often lacked detail of specific activities, they were quite powerful in conveying a sense of purpose.

We were surprised at how mature some of the content of the first year posters were, and what a comprehensive view they presented of PDP even at such an early stage of 
their course. We had over 50 posters from each of the year groups, so here we have only been able to present a sample. Figure 1 contains representative examples of the posters from first year students from four different courses: A) and C) are of the 'diagram' type, with a clear sense of progression and development of both academic and personal skills. Posters B) and D) are of the (mind-map' type, with B) showing slightly more sophistication in its structure, and greater depth in the number of elements and detail. For example, on time keeping D) talks about 'lecture and seminar deadlines', B) simply mentions 'diary' and 'start early'.

Poster A was from first year Biosciences students. This poster has a strong sense of progression through the years of their course, as did just over half of the posters from this group. It gives desirable academic and personal achievements at the top and bottom of the poster, and shows a clear sense of increasing independent learning through the three years, culminating in career-focused activity. Poster B was produced by students studying Forensic Science, and resembles a brain shower/mind map. Two of the five main groupings are categorised as 'academic' (writing and computer skills); two others are termed 'social' (social skills and enjoy uni), and the fifth is 'personal' (time management). The posters from other Forensic Science students were similar, with just under half incorporating some idea of progression through years one, two and three. Poster $\mathrm{C}$ was from a cohort of mature students on day-release from their jobs, studying Building Services. This poster resembles a crosshair, with widening, concentric circles signifying years one, two and three. There is a rational progression of items shown, e.g. report writing in year one, analytical skills in year two, and leadership/management in year three. It has also been divided into sections: work, personal, university, and workshops, and indicating in which sector different developments might occur. Similar concepts were seen in the other posters of this group. Poster D was created by students in Archaeology and, as with other posters from this group, has a stronger emphasis on personal qualities such as motivation and confidence, as well as personal organisation and time-keeping. 
ACADEMIC-OUT COMES (SKILCS).

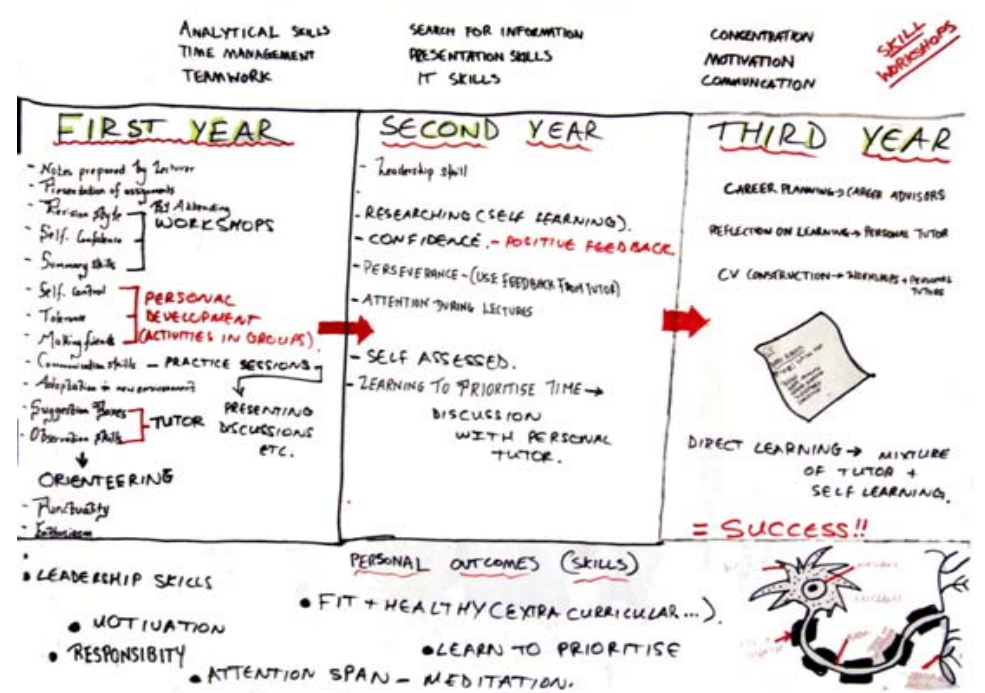
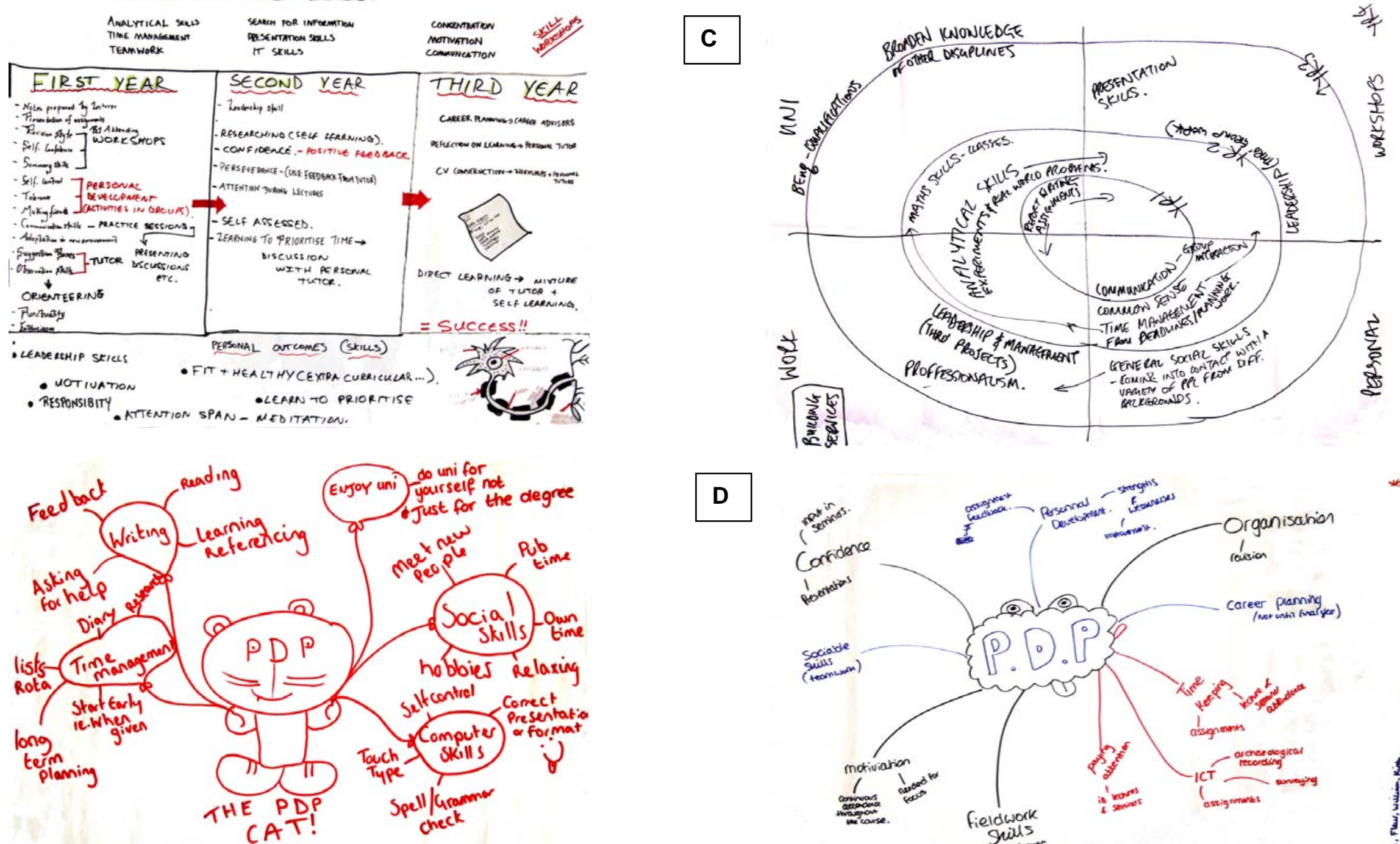

$$
16^{6 m} \text { Jan } 2009 \text { Forensic Science. }
$$

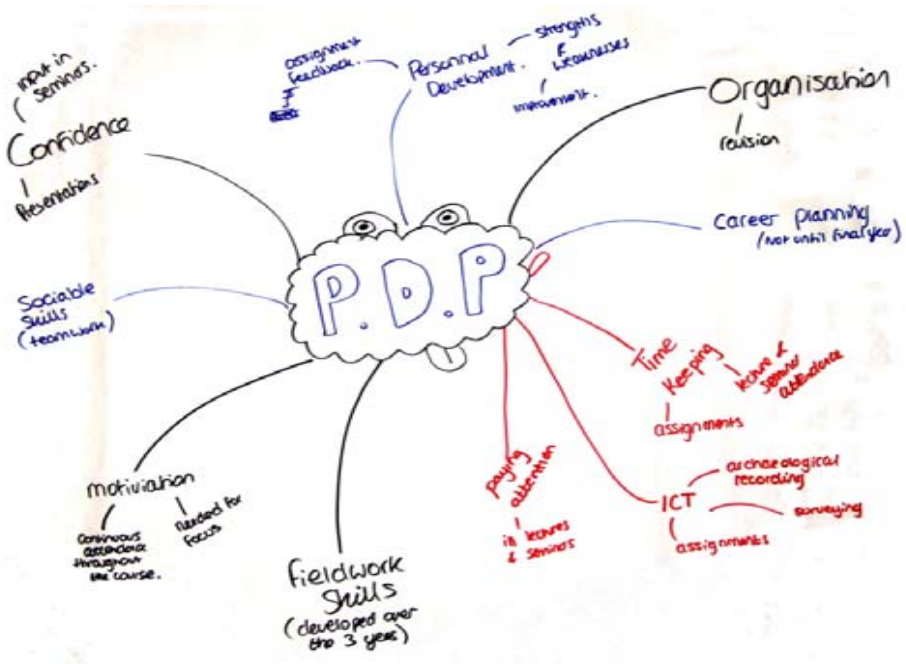

*

Figure 1. Sample from PDP posters collected from first year students (2008) studying A) Biosciences, B) Forensic Science, C) Building Services, D) Archaeology. 
The posters from second year students were different from the first years' in that a wider range of words or terms were used, there was clear evidence of learning from experience, a strong sense of personal development, and in several cases some value judgements identifying positive and negative experiences. The representation of progression through the years of the course was less marked than was the case with first years, in that there was less formal structuring into sections. The use of theoretical terms relating to a Further Education (FE) setting, or taken from the explanatory handout, were replaced by words relating to real life experiences: 'learn from mistakes'; 'don't leave things 'til the last minute'; 'need to manage stress'. Likewise, the wording does reveal that there is also some - possibly subconscious - action planning in evidence. Phrases such as 'start essays sooner', 'revise more', 'if finding a topic difficult, dedicate more time to it', 'discuss problems with tutor', 'attend career workshops', and 'attend BPSA conferences', could all be taken as instances of action planning, in that they are specific actions that have been articulated.

Four representative posters from second year students, from the same courses as represented in Figure 1 are shown in Figure 2, to illustrate these points. Poster AA, from students studying Biosciences, features a swan, which carries a positive message. It has been drawn on a line, showing education leading to a career, and therefore with some sense of progression. Terms such as 'constructive criticism from which you can learn', and 'discovering personal attributes through team work' illustrate a deeper level of selfawareness than in first year students, and this development of words/phrases is seen in all of the posters of this group. Poster BB was from the same Forensic Science students who drew the 'PDP cat' in their first year, and it has an identical structure. It is holding fewer balloons and has fewer terms, but more has been written on each, consistent with the overall trend noted above. Poster CC was from the Building Services students and is very visual, with each year represented by a different section of a rollercoaster. This poster also gives a key and written terms according to perceptions of good or bad, e.g. a good point is 'more respect from colleagues' and a bad point is 'tough assignments'. All the other posters from these students also used pictures and for these students there was a strong sense of progression; images included ladders and a roadway to illustrate this. These students seemed to have a clear grasp of the principles of PDP; the posters reflected both successes to date and an awareness of what they still had to achieve, although this was in broad terms with less detail of specific skills. Poster DD was from Archaeology students. As with others in this group, it is a very personal account but has more emphasis on 
academic development, compared with a stronger emphasis on social support seen in their first year posters. It also has some examples of action planning, with statements like 'organise a study group'; 'learn to use new technology'; and 'talk to family and friends'.

\section{Quantitative analysis of posters}

Examining the ranking of categories of words and phrases for posters from first year students revealed that across all eight courses, just three categories accounted for the highest rank position: 'personal' (in five courses), 'academic' (in two courses), and 'social/support' (the latter was unique to Archaeology). When the second ranked category was included, a further category, 'action planning', appeared, and if the third rank category was included, the 'reflection' category appeared, but only for Retail Management and Health and Social Care. There seems to be a degree of commonality of perception across courses, and this is related to the context of PDP, rather than the processes involved. There is also some evidence of course-specific cohesion, for example, Archaeology students from a small cohort of around twelve to fifteen, even at this early stage of the academic year, had spent some weeks together carrying out field work in a location away from the university.

In year two, five categories were represented in the top rank, with either 'career planning' or 'action planning' appearing in the top three for all the courses, and 'reflection' ranked either first or second for three courses. 'Personal' or 'academic' still featured but only appeared six times in the top two categories overall, compared with twelve times for first year students. This seems to suggest that there is a deepening awareness of what is involved in PDP, with a move towards a process focus, although this is still somewhat limited. However, aspirational terms relating to 'career' or 'action planning' are being used, for example, 'more idea/information on career opportunities' rather than a focus on specific activities to engage in. About $20 \%$ of the posters mentioned CVs and the majority of these were in Pharmacy, where 'career planning' was the first category, indicating the strong emphasis on professional development in this school. There is evidence here of an early emergence of situated practice (Becher and Trowler, 2001) in terms of student perceptions in individual disciplines. 
AA

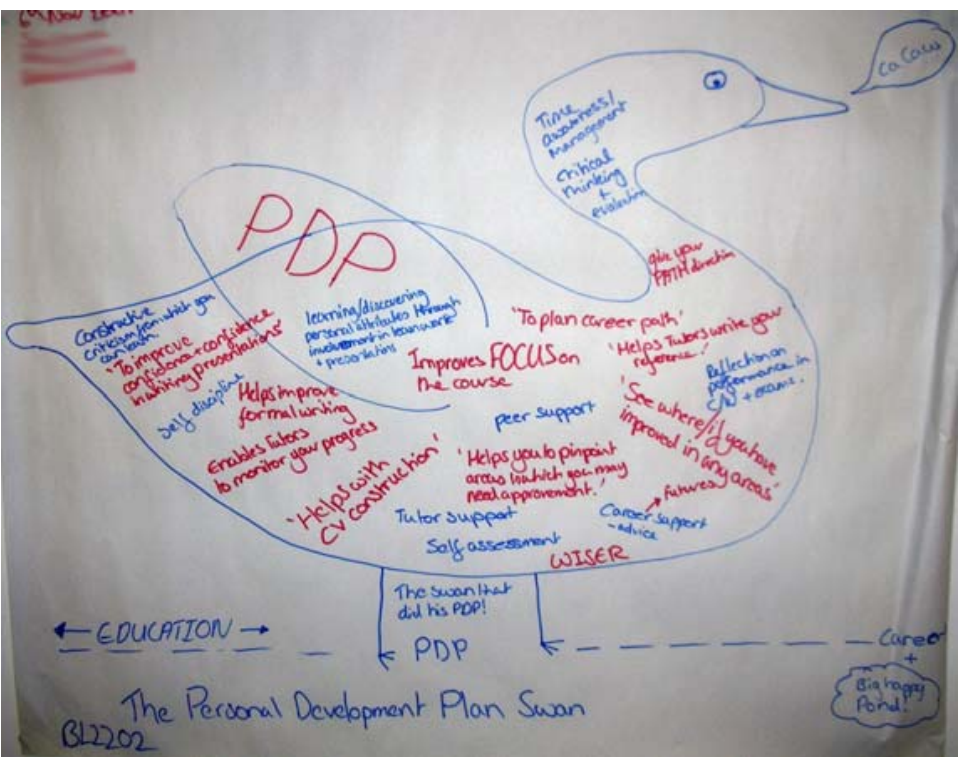

BB.

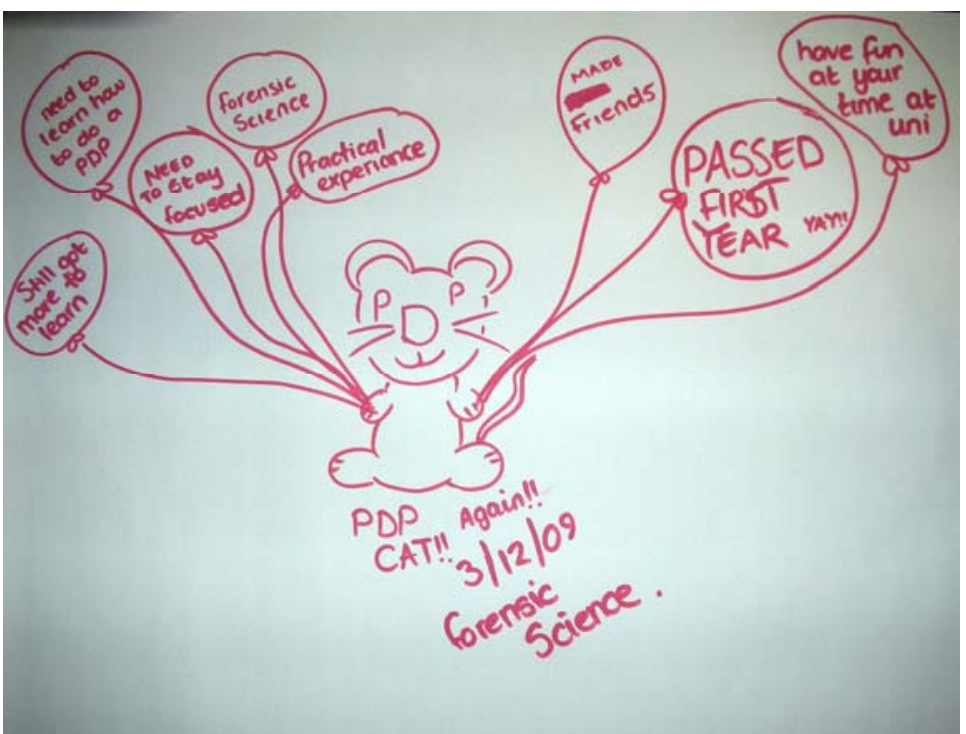

CC

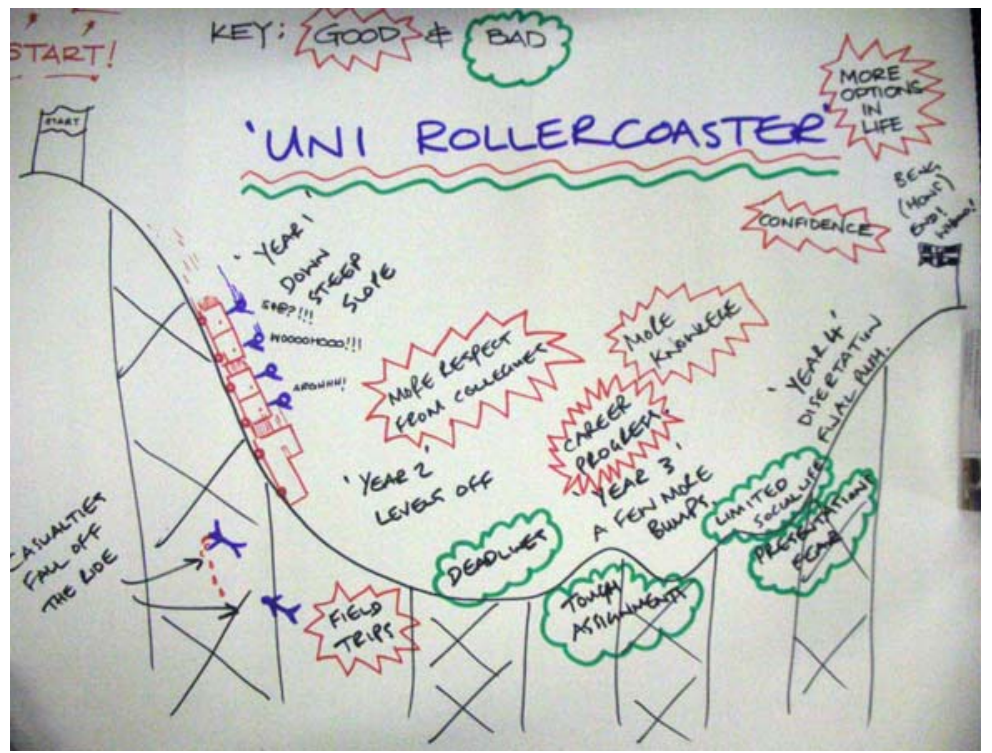

DD.

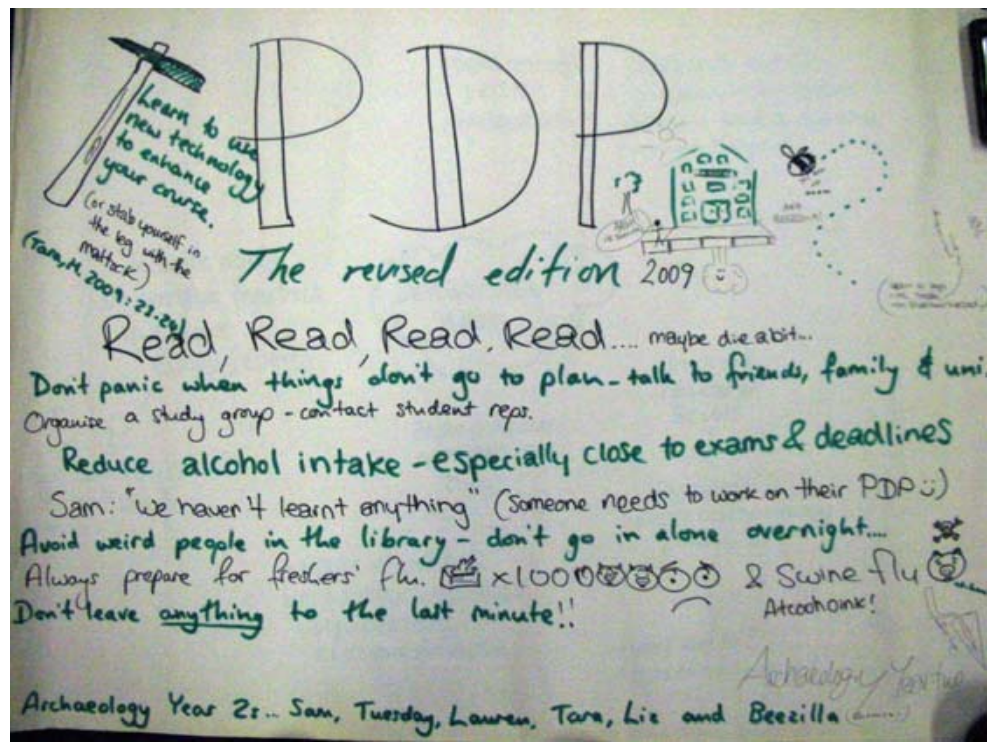

Figure 2. PDP posters collected from second year students (2009) studying AA) Biosciences, BB) Forensic Science, CC) Building Services, DD) Archaeology. 


\section{Individual responses}

\section{Post-it notes (year 1)}

The post-it notes were coded into the same categories as were the posters. Interestingly, just five categories were sufficient to fit the data. A detailed analysis was carried out on five of the courses and included first year groups from both 2008 and 2009 (the sessions with first year students were repeated in 2009). The results are shown in Table 2. Perhaps the most striking result is that on all of these courses the 'personal' category accounted for between $70 \%$ and $80 \%$ of the words or terms used; although this category was ranked first in the posters for five out of the eight courses, it did not account for more than $25 \%$ of the terms there. On the post-it notes, the most commonly used words or phrases related to time management, followed by confidence and motivation. These concepts are clearly recognised as personal priorities by first year students.

Table 2. Frequency of statements on post-it notes from first year students.

\begin{tabular}{|c|c|c|c|c|c|}
\hline \multirow{2}{*}{$\begin{array}{l}\text { Course (and } \\
\text { number of } \\
\text { notes) }\end{array}$} & \multicolumn{5}{|c|}{ Categories and frequency (\%) of occurrence } \\
\hline & Personal & Academic & Social/support & $\begin{array}{l}\text { Career } \\
\text { planning }\end{array}$ & $\begin{array}{l}\text { Negative (= } \\
\text { complaint) }\end{array}$ \\
\hline $\begin{array}{l}\text { Biosciences } \\
2008(98)\end{array}$ & 66 & 10 & 11 & 6 & 8 \\
\hline $\begin{array}{l}\text { Biosciences } \\
2009(37)\end{array}$ & 79 & 11 & 11 & 0 & 0 \\
\hline $\begin{array}{l}\text { Pharmacy } \\
2008 \text { (71) }\end{array}$ & 82 & 14 & 3 & 0 & 3 \\
\hline $\begin{array}{l}\text { Retail Man. } \\
2008(18)\end{array}$ & 72 & 28 & 0 & 0 & 0 \\
\hline $\begin{array}{l}\text { Retail Man. } \\
2009 \text { (19) }\end{array}$ & 79 & 21 & 0 & 0 & 0 \\
\hline $\begin{array}{l}\text { Building } \\
\text { Services } 2009 \\
(23)\end{array}$ & 74 & 22 & 4 & 0 & 0 \\
\hline $\begin{array}{l}\text { Archaeology } \\
2009 \text { (10) }\end{array}$ & 80 & 20 & 0 & 0 & 0 \\
\hline
\end{tabular}




\section{Questionnaire responses (year 2)}

Of 189 responses, 105 indicated that their expectations of PDP had been met, 74 said they had not been met, and four that they had been exceeded. The comments made were more extensive than the short phrases on the first year post-it notes, and instead of coding these, we have looked at them across all courses in terms of positive perceptions (expectations met) or negative perceptions (expectations not met). Examples of statements from those who said expectations had been met are given below.

Biomedical Science students:

- Learned to become responsible and be able to organise lessons/assignments, hand in assignment on deadline.

- Self-awareness has improved because I am better at time management. I reflect on each task I have to do and work at how I will do it. I action plan each task I am given by writing a list. I update my CV when I achieve new skills and qualifications.

Bioscience students:

- Not all work done at last minute; have begun to start assignments early. Have used library more. Passed first year with decent grades.

Pharmacy students:

- Improved time management. Good team work. Career planning has improved since summer placement.

- We are constantly told to reflect on our learning and how we can put anything we have learnt into practice.

Building Services students:

- I have got better at time management and I am more active in groups, and I have finally started to learn the guitar.

- I am now able to manage my time more effectively and complete tasks by deadlines. I have become more confident when giving presentations than I was last year. 
What these comments seem to show is a strong sense of personal growth - self-

awareness, self-confidence, and improvement in skills such as time management and selforganisation.

For students who reported that expectations were not met, one of three scenarios seems to apply: 1) some students do understand the principle of PDP and are aware that they are not managing to do it; 2) others have not engaged with the ideas at all; and 3) some sense a problem with the way in which PDP has been undertaken on their course:

- Not as organised as last year. There are too many assignments all at once so it's difficult to stay on top. But still trying to learn and understand what is going on with time. (Scenario 1)

- Achieved well last year. Since then pressure and disorganisation has meant the PDP expectations have gone downhill. (Scenario 1)

- PDP did not stick in my memory. As it did not seem to be of any relevance at the time. ( Scenario 2)

- Don't really know what to do for it. Different lecturers giving conflicting comments. (Scenario 2)

- Was never properly explained how to do PDP, there was no way to know what to do. (Scenario 3)

\section{Discussion}

This work has shown that while student understanding of PDP in a strictly formal sense may be limited, there is clear evidence of a deepening of their engagement in various aspects of personal development as they progress from first to second year. The content of their posters showed a greater maturity in year two: the representations were less reliant on the PDP framework given to them and there was more evidence of activities, such as reflection and action planning, which contribute to the process of PDP rather than just the context. The ranking of categories also supports this. Words and phrases in the 'personal' and 'academic' categories were less prevalent in the year two posters, while those in the 'action planning' and 'reflection' categories were more prevalent than in the year one posters. Savory (2007), commenting on the findings reported by Clegg (2006), reached a similar conclusion - while first year students were concerned with practical 
study issues, third year students were engaged with reflection on skills and approaches to learning. Reassuringly this is also in line with the perspective of employers: 'most employers put strongest emphasis on the process of PDP rather than the documented outcomes' (Edwards, 2005, p.3).

A deepening engagement in personal development was also to be discerned in the individual responses elicited through post-it notes (year one) and questionnaires (year two). For first years there was a very strong focus on, and awareness of, need in the area of personal effectiveness, such as time management, motivation and self-confidence. By the second year these same students were able to recognise achievements in these areas. Comments from second years also provided evidence of progress in other aspects of PDP - reflection, self-awareness and group-work. Although less easy to discern, the fact that achievements were recognised could indicate that action planning had taken place; further, some of the specific wording on second years' posters constituted identified actions to be taken.

We have been reassured that students are recognising their development needs, and their achievements, and that this is despite the fact that most students reported that they had had little, if any, guidance on PDP from their own tutors. Powell (2010), in this volume of the Journal of Learning Development in Higher Education, reports that staff view the individual elements of PDP more positively than they do the term PDP itself, and we suspect that the term PDP may no longer be helpful in achieving the ends for which it was originally introduced. Students probably have a similarly negative view of the term. In a survey, Moir et al. (2006) found that fewer than $25 \%$ of students felt that PDP was beneficial to their academic studies, while slightly more said that the reflection was beneficial. Our experience is that if it is explained, then most students do understand the principles of PDP, and indeed many of the comments suggested that they would value more time being devoted to this area.

Our approach, of using posters as a research tool, actually seems to have been successful in encouraging learning, and might be useful in other situations. It can be seen as firmly based in situated learning theory (Lave and Wenger, 1991), in that we introduced the students (novices) to PDP, and through getting them to work together on defining PDP, interacting and engaging with each other and the tutors (experts), we communicated PDP concepts and language to help them move towards being masters of PDP. As they 
become more expert in PDP, they are less reliant on our framework and are developing their own framework (which fits within the wider concepts of PDP). Within this view, knowledge is dynamically constructed as we perceive what is happening to us and as we talk and move in social situations (Clancy, 1995). So, although they might not formally articulate this development as PDP, students are actually learning the associated language and the associated PDP activities and processes through their own experiences, and through collaboration with each other. Thus they are slowly moving towards becoming experts themselves and being able to take charge of their own personal development.

An extension of this study to final year students could therefore have a dual benefit, providing a further opportunity for students to actively and consciously engage in a review of their personal development (a learning benefit); and secondly, to reveal the perceptions of final year students and whether there has been a further development from their second year (a research benefit). This will complete a longitudinal study of student perceptions of PDP and the further insights gained will provide valuable information to share with staff, and which in turn we hope will inform and enhance their practice.

\section{Acknowledgement}

This paper is an outcome of the National Action Research Network on researching and evaluating Personal Development Planning and e-Portfolio practice project (2007-2010). The project was led by the University of Bolton in association with the University of Worcester and Centre for Recording Achievement, and in national collaboration with the University of Bedfordshire, Bournemouth University and University of Bradford. The project was funded by the Higher Education Academy, National Teaching Fellowship Project strand. More details about the project can be found at: http://www.recordingachievement.org/research/narn-tree.html.

We are grateful to colleagues from the project for stimulating discussions. We are also grateful to Derek Heim, School of Psychology, UCLan, for advice on the presentation of data. 


\section{References}

Becher, T. and Trowler, P. (2001) Academic tribes and territories. 2nd edn. Buckingham: Open University Press.

Bloxham, S., Cerevkova, A. and Waddlelove, C. (2007) 'Embedding personal development planning within a Web-CT supported module - a collaborative venture', Practitioner research in Higher Education, 1(1), pp. 3-9.

Brennan, J. and Shah, T. (2003). Access to what? Converting educational opportunity into employment opportunity [final report]. London: Centre for Higher Education Research and Information. Available at: http://oro.open.ac.uk/6554/ (Accessed: 29 September 2009).

Clancey, W. (1995) 'A tutorial on situated learning', in Self, J (ed.) Proceedings of the international conference on computers and education, Taiwan. Charlottesville VA: AACE, pp. 49-70.

Clegg, S. andBradley, S. (2006) 'Models of personal development planning: practice and processes', British Educational Research Journal, 33(1), pp. 57-76.

Dearing, R. (1997) Report of the national committee of inquiry into higher education. Available at: http://www.leeds.ac.uk/educol/ncihe/ (Accessed: 28 May 2010).

Edwards, G. (2005) Connecting PDP to employer needs and the world of work. York: HEA. Available at:

http://www.heacademy.ac.uk/assets/York/documents/resources/resourcedatabase/i d71 connecting pdp to employer needs.pdf (Accessed: 9 November 2010).

Lave, J. and Wenger, E. (1991) Situated learning: legitimate peripheral participation. New York: Cambridge University Press.

Lumsden, P. (2005) 'Building personal development planning into the curriculum', Planet, 15, pp.33-35 [Online]. Available at: http://www.gees.ac.uk/planet/p15/pl.pdf (Accessed 1 May 2010). 
Lumsden and Davey From cats to roller-coasters: creative use of posters to explore students' perceptions of PDP

Moir, J., Di Domencio, C., Vertigans, S. and Sutton, P. (2006) Perceptions of personal development planning in sociology and social science: the Scottish higher education context. York: Higher Education Academy. Available at: http://www.csap.bham.ac.uk/media/com projectlog/docs/40 S 06.pdf (Accessed: 9 November 2010).

Powell, J. (2010) 'Useful or just another fad? Staff perceptions of personal development planning', Journal of Learning Development in Higher Education, Special Edition [Online]. Available at: http://www.aldinhe.ac.uk/ojs/index.php?journal=jldhe (Accessed: 3 October 2010).

Quality Assurance Agency (2009). Personal development planning: guidance for institutional policy and practice in higher education. Available at: http://www.qaa.ac.uk/academicinfrastructure/progressfiles/guidelines/pdp/pdpguide. pdf (Accessed: 3 October 2010).

Savory, J. (2007) 'I never thought how I learn, just that I learn ......' - An evaluation of the impact of embedding personal development planning (PDP) processes and the effect on independent learning. Salford: University of Salford. Available at: http://www.ece.salford.ac.uk/proceedings/papers/34 07.pdf (Accessed: 1 May 2010).

Stefani, L. (2005) PDP/CPD and e-portfolios: rising to the challenge of modelling good practice. Auckland: University of Auckland. Available at:

http://74.125.155.132/scholar?q=cache:yXSfagxZFp0J:scholar.google.com/+Lorrain $\underline{\text { e+Stefani+2005\&hl=en\&as } \mathrm{sdt}=2000}$ (Accessed: 21 January 2010).

Strauss, A. (1987) Qualitative analysis for social scientists. Cambridge, England: Cambridge University Press.

\section{Author details}

James Davey is a former undergraduate Neuropsychology student at UCLan and is now working at UCLan as a Research Assistant. 
Peter Lumsden has a PhD in Plant Science and was an active researcher in the field of flowering and photoperiodism for 20 years. He is currently an Academic Developer within the Learning Development Unit at UCLan. His particular interests are in Feedback, PDP and the use of coaching approaches throughout HE. 